AC 2008-1743: A SUCCESSFUL MODEL FOR ENGINEERS STUDYING ABROAD: A FOREIGN STUDY CENTER WITH CONCURRENT INSTRUCTION

Michelle Clauss, Grove City College

Blair Allison, Grove City College

Mark Reuber, Grove City College

Stacy Birmingham, Grove City College

Vincent DiStasi, Grove City College 


\title{
A Successful Model for Engineers Studying Abroad: A Foreign Study Center with Concurrent Instruction
}

\begin{abstract}
In the fall of 2006, Grove City College offered for the first time the option of studying abroad for an entire semester to junior mechanical engineers. This opportunity involved the establishment of a study center in France (associated with the University of Nantes) along with remote instruction in two courses concurrently taught in France and in Grove City, PA. Although students in other majors have had the chance to study a semester or even a year abroad, this opportunity has typically eluded the engineering majors. Finding comparable course offerings at foreign institutions is often difficult. Therefore, students desiring to remain in sync with their classmates decide not to go. Still, it is well accepted that engineers of today must function in a global society. Greater exposure to different cultures will prove to be an invaluable asset to the student as well as their future employer. Thus, the Office of International Education at Grove City College designed and implemented a study-abroad program directly targeting mechanical engineers. This program involved two courses taught concurrently by professors at Grove City College, a laboratory experience making use of the facilities at the University of Nantes and additional equipment brought from the United States, a course taught by one of the resident professors staying at the study center, and a foreign language course taught by a second resident professor. Students also were exposed to living and interacting in a foreign community, exploring industrial facilities in the country, and making invaluable contacts with foreign employers.
\end{abstract}

The typical concerns of studying abroad were eliminated with the new approach. These issues centered on equivalent academic experience, academic rigor, remote teaching tools (GoToMeeting and DyKnow) used with TabletPCs and their effectiveness, study center versus full immersion model, and more. Through careful assessment, it was shown that the pilot semester abroad opportunity was successful in all aspects. The students in France performed as well as the students on the Grove City campus in the two concurrent courses. In addition, the students in France perceived no difficulty receiving the lectures remotely, and were encouraged to submit graded assignments electronically using their TabletPCs which greatly facilitated the transfer of documents between Grove City and France. An unexpected finding of the assessment was that some students who studied abroad improved their academic standing. This was attributed to the immersion of the students in a residential study center and the constant availability of other mechanical engineering students as study partners. This program is now in its second year, and assessment data from this year is used to further support our conclusions regarding the effectiveness of this study-abroad model.

\section{Introduction}

In 2004, Grove City College selected a cross-discipline, multi-level team whose goal was to develop a strategic plan which will propel the College into the future. Administration, faculty, staff, students, alumni, members of the local community, and Trustees were represented on the team. After a year of intensive investigation and discussion, a plan was submitted for approval to the Board of Trustees. The plan was accepted and has been used to direct the progress of the 
College since its adoption in 2005. One of the many strategic initiatives set forth by the plan was the recognition that in order to continue to enhance excellence in the academic offerings of the College, a broadening of academic opportunities had to occur so that those graduating will possess skills and abilities necessary to become leaders in a global community.

The Director of the Office of International Education examined the study abroad offerings available at the time for Grove City students and found the need for programs targeting students in science, engineering, and mathematics. With only $5 \%$ of the students enrolled in the Hopeman School of Science, Engineering, and Mathematics participating in studying abroad at least a semester, it was obvious that this group needed more options available as well as encouragement to take advantage of international program offerings. In addition, the overwhelming majority of the Hopeman School students that did participate in study abroad opportunities were Pre-Med majors. Less than $0.1 \%$ of all students studying abroad were from the remaining science, engineering, and mathematics disciplines, which included biology, chemistry, physics, electrical engineering, mechanical engineering, computer science, and mathematics.

With today's pervasive global economy, it is logical to focus attention on creating opportunities for those under-represented majors which are vital for the expanding world commerce.

Technology is an obvious avenue through which the world surges forward. Thus, engineers in particular must be prepared to understand, work, communicate, and live in a multi-cultural environment. This led to the decision to develop a semester-long study-abroad option for junior mechanical engineering majors.

The unique aspects of this program, based on establishing a study center in Nantes, France with some courses taught remotely on the Grove City College campus, will be described in this paper. Data taken from two semesters (two years) of this pilot program show that students enrolled in this study-abroad option do as well as, and in some cases better than, their colleagues on the Grove City College campus. Lessons learned regarding technology to facilitate instruction and immersion of the students in the culture will also be addressed.

\section{Background}

\section{Brief Overview}

When designing a new international course or program, one of the first questions which must be addressed is length of stay. This typically breaks down into either two-week (intersession), sixweek (summer), one semester, or full year options. A brief overview of some of the options that have been available in recent years will be presented.

Many schools offer two-week study-abroad courses. At the University of Pittsburgh through their Plus 3 Program, first year students have been able to take a three credit international study course where the student spends two weeks abroad viewing various guest lectures and cultural visits ${ }^{1}$. Mississippi State University also has offered an intersession option specifically designed to increase study abroad choices at affordable costs to the student ${ }^{2}$. Two-week courses fill a niche; however, they give limited cultural experience due to their short time period. They do 
eliminate concerns over "getting off track." This is a significant concern for engineering majors since their programs are very rigid and typically have few electives. These options can also be completed in time for students to participate in summer internships and employment. A variation of the two-week intersession options has been the "Engineering Practice in Europe" and "Engineering Practice in Asia" programs available at Mississippi State University". These provide two weeks of field experience for the engineering student in a foreign land.

Still another popular option is the six-week summer program offered at various universities and colleges. These programs provide longer cultural exposure while still not requiring a semesterlong time commitment. This can be more enticing to students if the location of study is a site with an extremely different culture. The University of Arkansas offered a six-week pilot program in 2006 to India ${ }^{3}$. Students earned six credits and took two courses, an engineering elective taught by a University faculty member and a humanities elective taught be an Indian professor. The University of Texas at Austin has also offered several six-week, six credit programs ${ }^{4}$. Students are encouraged to travel while studying abroad since the program is arranged to have no classes on Friday through Sunday.

Many universities and colleges have long offered semester study-abroad programs often through third party organizations. Grove City College has participated in such programs throughout the years; however, engineering majors have never been able to take part without significant issues associated with transferring of credits and remaining "in sync" with their peers. Lafayette College engineering students have been able to spend a spring semester in Brussels studying at Vesalius College 5 . While there, students took four courses with two of them being a foreign language and an art history course. Students stayed with host families. Boston University, Kettering University, and Iowa State University are just a few of those offering traditional studyabroad options to their students. These students study at foreign universities and stay either in dormitories or host homes ${ }^{6,7,8}$. In addition, Mississippi State University through Global Engineering Education Exchange (Global E3) offers engineering students a semester abroad option $^{2}$.

Finally, a few programs center about a full year abroad. The University of Birmingham's MEng International Study Program expects students to study a year at a foreign institute? ${ }^{9}$ The University of Rhode Island along with Technische Universitat Braunschweig has a dual degree program where engineering students receive an engineering degree as well as a foreign language degree $^{10}$. The program typically takes five years to complete. Virginia Tech engineering students can receive a dual degree from either Technische Universitat Darmstadt or the Royal Institute of Technology (Stockholm, Sweden) ${ }^{1}$. Students spend their senior year at the foreign facility, then earning them a degree from this site as well as Virginia Tech.

Still another consideration is that international experience does not have to be limited to academics. Students can obtain work experience through foreign internships, co-op work abroad, and even volunteer programs such as Engineers Without Borders.

When to offer the program must also be decided. Obviously, shorter study-abroad options are more flexible and can be offered during intersession or summer terms. Semester programs could be during the fall, spring, or summer. Georgia Tech, through its Lorraine campus, offers summer 
classes for its undergraduates ${ }^{11}$. However, there are many compelling reasons behind having a full semester abroad, with increased foreign contact being one of the strongest. This is why a semester program was chosen.

Grove City College already provided a variety of options for their students in order to acquire international experience; these include two-week courses (both intersession and summer) and the traditional semester abroad through a third-party organization. The number of two-week courses has increased in recent years as the need for global experience has increased. These options range from humanity to engineering electives. Students typically earn three credits for these courses. Still, two weeks is only a limited exposure to a different culture. Semester-long programs often do not meet the requirements for certain majors including mechanical engineering. They do provide a fully embedded experience which is obviously key to an international experience. Notwithstanding, finding a program that met the same academic criteria and course scheduling as that provided by Grove City College was difficult. A new program addressing these concerns was devised. Six key reasons were found to support the development of a study-center approach. First, high demand by students and parents existed. Parents desired a safe location for study. The events of and following September 11, 2001 have been a key driving force for an increased demand for safety. Students also desired an option that would eliminate issues such as transferring credits and give them the invaluable opportunity of international knowledge. All courses offered at the study-center would be Grove City College courses. Second, a study-center with courses taught primarily by Grove City College professors would be the only way certain majors could experience a semester abroad. Problems such as remaining "in sync" with peers and the same academic standards can be controlled. Third, this program would open an avenue for Grove City College faculty to receive more international exposure as well. Those teaching courses are given the opportunity to go to France for part of the semester. Fourth, the cost would be half that of competing programs. Fifth, a study-center would provide an extension of the Grove City brand and quality. Students coming to Grove City College are expected to abide by specific rules of conduct. In most cases, these rules are simply extensions to their homes. Finally, the study-center option would be a great compliment to our existing international programs. Students would take the same core courses with the added component of a foreign language deemed key to the overall experience.

\section{Program Details}

In the fall of 2006, Grove City College provided a new educational opportunity for junior mechanical engineering majors. Through a joint agreement with the University of Nantes, Grove City College established a study center where students could stay at a centralized facility under the supervision of two Grove City College professors. To ensure the academic rigor of the courses, two required mechanical engineering courses were taught on the Grove City College campus and delivered in real-time to the study center in France. The study center was equipped with Internet access which provided the means by which remote courses could be delivered as well as wireless network access. The students also had access to various facilities at the University of Nantes including the engineering laboratories.

Learning to live in a foreign culture was achieved through various means. Students were involved in all daily living activities including cooking and maintenance of the center. Students 
had to grocery shop and communicate with those at various stores. They also were involved with a local church as well as contact with University students through Ecumenical organizations. Students have also commented that they have had contact through "pick up" soccer games, playing Frisbee, and simply by being in the city.

To better understand the culture and country in which they stayed, all students were required to take French. One of the resident professors taught the course. Students learned basics and were encouraged to hone these students through communication with local French residents.

The study center itself is staffed by a faculty couple who act as both resident directors and instructors. Both faculty speak French and English and supervise as well as assist in the daily running of the center, including meal preparation, cleaning, mechanical and electrical repairs, running of the wireless computer network, and computer repairs. These are all done with some degree of student assistance ranging from minimal to significant.

To assure a contiguous, equivalent academic program, all courses were taught by Grove City professors. Two courses, Fluid Mechanics and Mechanics of Materials (taken by all junior mechanical engineers), were taught simultaneously at Grove City and France. This was accomplished through the aid of a speaker phone system and the Internet. A high fidelity speaker phone was used at both sites. This provided two-way audio communication, allowing the students in France to hear the lecturer and to ask questions. Two different means were used to deliver the visual component of the lectures: DyKnow (used to teach Mechanics of Materials) and GoToMeeting (used to provide Fluid Mechanics). DyKnow, a client/server based product, creates an immersive experience and promotes interaction and active learning by collaborative note taking, student response tools (anonymous polling), and electronic submission and collection of student work. For the Mechanics of Materials course, the tool used most within DyKnow was the collaborative note taking in which the instructor shares content (diagrams and notes written in real time; progressive disclosure) with students where the students can take additional notes directly on the content or alongside the delivered slides in a private notes section. Although DyKnow provides many additional features, these were not used by the remote course. GoToMeeting, a web-based product which permits simultaneous delivery of all visual aspects associated with a controlling TabletPC, was used to deliver the Power Point presentation and annotations for Fluid Mechanics. With both software applications, the presentations were projected onto a large screen at both sites allowing students to see all notes written by the professor while listening to the lecture. The ability to write on the TabletPC was critical for these instruction applications.

Two additional courses, a junior level instrumentation laboratory course and Engineering Management, were taught by one of the resident professors. The junior Mechanical Engineering lab course (taken by all junior mechanical engineers) made use of equipment brought from Grove City College as well as available through labs at the University of Nantes. The Engineering Management course incorporated field trips to local sites, exposing students to foreign industrial facilities, French management practices, and contact with French engineers. This opportunity provided invaluable networking with potential employers, such as Poclain Hydraulics, Inc., an international manufacturer of Hydraulic motors. Both of these courses introduced the student to working in a foreign environment. 
There were three minor curriculum differences between the "typical" junior fall semester for a mechanical engineering student and that experienced by the students studying in France. Our students in the U.S. normally take 16 credit hours of required engineering and general education courses. The students in France take only 13 credit hours, including the elective introductory French class. The shortage of 3 credit hours is associated with a general education humanities course. This is taken by the France students during their senior year in a semester that typically has a lower credit load. Second, the students studying in France did not take the Mathematical Methods in Engineering course typically taken in the fall semester of their junior year. Instead, this course is taken the following spring semester during a curriculum slot normally associated with a mechanical engineering elective, already taken by those in France (Engineering Management). Third, the French course taken by all students studying in France counted as a general elective. Typically, students wait to take their general elective during their senior year. However, this re-shuffling of the curriculum does not impact the graduation date or require any overloads for students studying abroad.

In addition, delivery of remotely taught courses on a Tuesday-Thursday schedule and the on-site courses on Wednesdays and Fridays, provided for a four-day lecture week. This facilitated travel time to engineering sites as well as personal travel by the students. Students appreciated both opportunities and mentioned the benefit of such a schedule. It was seen that students took advantage of the opportunity to visit many different locations, both within France and to other countries. A few of the countries visited by students included England, Ireland, Italy, Austria, and Germany. Finally, the affordability of the option was enticing to the student. The program cost (including air fare) for the student was made identical to the current tuition, room and board charges at Grove City College plus a nominal fee $(\$ 500$ - \$700). This was done to lower the barrier to international study, which for many students is primarily financial. Excluding start-up costs, the program is self-sustaining and breaks even.

\section{Typical Concerns and Results of the Pilot Program}

One of the first concerns of the pilot program was associated with the lecture delivery system. Since two courses were to be remotely taught by professors in Grove City, a robust means of delivering lectures was critical. During the spring semester in 2006, the proposed delivery system was tested. For two weeks, students planning to study abroad were located in a remote classroom on the Grove City College campus during Mechanics II (Dynamics). This course was taught by the same professor that would be teaching the remotely delivered Fluid Mechanics class. Using the speaker phone system and GoToMeeting, the students were exposed to a simulation of the remote learning environment. All students in the course then took an exam on the material covered that two-week time period. This allowed us to determine if remote teaching would affect the student's performance on exams since the only variable changed was the means of delivering the lectures. The mean score on the exam for the students located in the same classroom as the instructor was found to be $82.8 \%(\mathrm{~N}=31, \mathrm{SD}=18.0)$ while the mean score for those remotely located was $81.9 \%(\mathrm{~N}=13, \mathrm{SD}=9.5)$. A t-test indicated no statistical difference between the two sets $(\mathrm{t}(42)=0.17, \mathrm{p}=0.86)$. However, this assumes the two groups are not originally different. Thus, the final grades for the two groups were compared. Those students in the same class earned a mean grade of $80.6 \%(\mathrm{~N}=31, \mathrm{SD}=7.2)$ while those remotely taught 
scored a mean value of $81.6 \%(\mathrm{~N}=13, \mathrm{SD}=13.1)$. A t-test showed no statistical difference between the groups $(\mathrm{t}(42)=0.23, \mathrm{p}=0.82)$. From a survey administered immediately following the experience, seven of the nine students that responded to the survey indicated that the means of delivery was either had no impact or was better for the student's learning. The simulation was again repeated in the spring of 2007. Once again, similar results were found. On the exam, the mean score for those students in the same classroom as the instructor was $81.6 \%(\mathrm{~N}=15$, $\mathrm{SD}=11.5)$ while those remotely located had a mean of $80.9 \%(\mathrm{~N}=14, \mathrm{SD}=8.3)$. Again a t-test indicated no statistical difference between the two groups $(t(27)=0.20, p=0.84)$. Final grades were compared. It was found that those in the same classroom had a mean value of $82.1 \%$ $(\mathrm{N}=15, \mathrm{SD}=8.5)$. Those remotely earned a mean of $84.5 \%(\mathrm{~N}=14, \mathrm{SD}=5.4)$. A t-test again showed no statistical difference between the groups $(\mathrm{t}(27)=0.91, \mathrm{p}=0.37)$.

In addition, a survey given at the midterm of the first year of the program asked the students if the remote lectures were working well and if they understood things sufficiently; all students indicated that the process was going well and that they were able to grasp the information as well as, if not better than, being in the same classroom as the instructor. The same survey given the second year yielded the same results; all students found very little difference between remote and classroom instruction.

In addition, the two delivery modes (DyKnow and GoToMeeting) were compared through a survey question posed to both the 2006 and 2007 programs. The question was "How do you compare DyKnow and GoToMeeting?" From the first year survey results, students gave a mixed response. Some (two out of the eleven responses) preferred DyKnow since it provided all the Power Point slides with the notes written by the instructor. Embedded images reduced the time spent during class copying diagrams while trying to keep up with the lecture. Still others (three out of the eleven responses) found GoToMeeting sufficient for their needs. Some students preferred taking their own notes with paper and pen and remained indifferent to either mode (four out of the eleven responses). The remaining responses indicated both modes were the same to them (two out of the eleven responses). From the second year survey results, again students gave a mixed response. Three students out of fifteen preferred DyKnow over GoToMeeting; their main reason was the availability of instructor's notes on the Power Point slides. Six of the fifteen preferred GoToMeeting; the main reason for this response was that it forced the student to pay attention and write notes. Four students thought the two modes were equivalent and two students were indifferent. In all cases, students found the two applications sufficient for the delivery of the lecture component of the remotely taught courses.

Equivalent academic experience and rigor were also concerns. As discussed above, the academic experience of the students in France was similar to that of the students on the Grove City College campus with the exception of the course in French and the Engineering Management course. To examine if the academic benefit and rigor were the same with both sets of students, the grades on all exams and the final grade for students in France were compared to those remaining at Grove City. This data is summarized in Table $\mathbf{1}$ for both remotely taught courses. As clearly noted, the academic performance assessed through comparing those at Grove City with those students in France was statistically the same. This was found to be true for both remotely-taught courses. 


\section{Table 1}

\section{Fluid Mechanics \\ - Exam Grades}

2006 - First Year

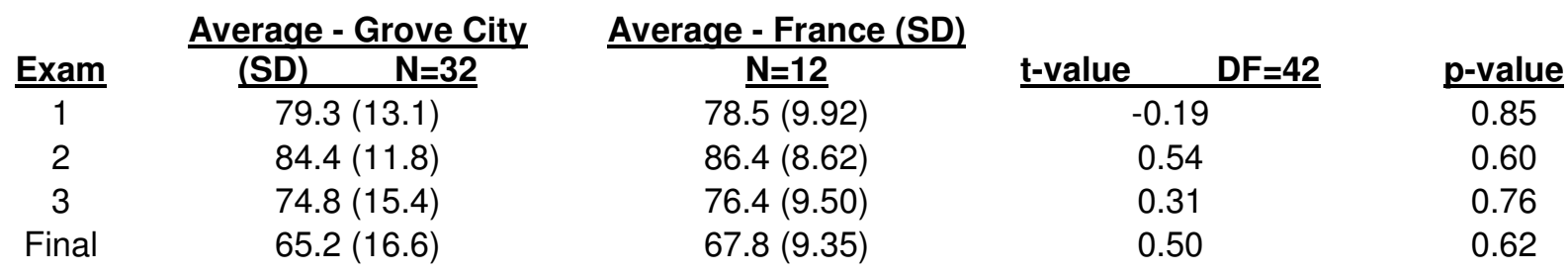

2007 - Second Year

\begin{tabular}{cc} 
Exam & \multicolumn{2}{c}{ Average - Grove City } \\
\cline { 2 - 2 } 1 & $\frac{\mathbf{S D})}{\mathbf{N}=17}$ \\
2 & $74.6(9.01)$ \\
3 & $71.0(20.6)$ \\
Final & $82.5(9.08)$
\end{tabular}

Average - France (SD)

$\mathrm{N}=15$
$82.6(9.25)$
$74.1(14.1)$
$81.3(7.74)$
$77.5(11.4)$

\begin{tabular}{ccc} 
t-value $\quad$ DF=30 & & p-value \\
\hline 0.63 & & 0.53 \\
0.48 & 0.63 \\
-0.38 & 0.71 \\
0.04 & 0.97
\end{tabular}

\section{Mechanics of \\ Materials - Exam Grades}

2006 - First Year

\begin{tabular}{cc} 
Exam & \multicolumn{2}{c}{ Average - Grove City } \\
1 & $\frac{\mathbf{S D}) \quad \mathbf{N}=33}{80.2(15.0)}$ \\
2 & $87.7(12.7)$ \\
3 & $79.8(13.3)$ \\
Final & $79.9(16.7)$
\end{tabular}

Average - France (SD)

$\frac{\mathrm{N}=12}{77.3(12.1)}$
$90.4(9.41)$
$77.6(14.9)$
$84.0(8.38)$

\begin{tabular}{ccc} 
t-value $\quad$ DF=43 & & p-value \\
\hline-0.59 & & 0.56 \\
0.68 & & 0.50 \\
-0.49 & & 0.63 \\
0.82 & & 0.42
\end{tabular}

2007 - Second Year

\begin{tabular}{|c|c|c|c|c|}
\hline & Average - Grove City & Average - France (SD) & & \\
\hline Exam & (SD) $\quad \mathrm{N}=14$ & $\mathrm{~N}=15$ & t-value & p-value \\
\hline 1 & $81.9(15.7)$ & $88.1(7.50)$ & 1.39 & 0.18 \\
\hline 2 & $78.9(8.45)$ & $81.3(11.5)$ & 0.62 & 0.54 \\
\hline 3 & $87.4(7.88)$ & $83.5(13.5)$ & -0.94 & 0.36 \\
\hline Final & $87.0(8.77)$ & $82.8(8.98)$ & -1.27 & 0.21 \\
\hline
\end{tabular}


Another concern was associated with the transfer of graded information between the two countries. For the first year of the program, students were encouraged but not required to use their TabletPCs for the preparation and electronic transmission of homework. Students often used OneNote, a Microsoft product available on the TabletPC. It was extremely easy for the instructor to have OneNote documents delivered, graded, and returned through e-mail. An additional benefit was the automatic archiving of graded work for ABET documentation. For those students not desiring to use their computers for homework, scanned copies of homework were sent as e-mail attachments. During the first year of the program, these scanned documents were imported into OneNote, graded and then returned via e-mail. A similar process was used for exams. The resident professor in France scanned the exams into the computer and then sent them as e-mail attachments to the course instructor in Grove City. The process, under normal conditions, permitted the instructor to receive exams from France within two days. This time delay was purely related to the schedule limitations of the resident professor. For the second year of the program, scanned documents were viewed and graded within Microsoft Word. This change drastically reduced the scanning rate. All homework was prepared on the students' TabletPCs and sent individually via e-mail. The process went very smoothly. Once again, a TabletPC was crucial to facilitate grading homework and exams. The benefit of automatic archiving of graded work resulted as before. This really was a time-saving benefit since the instructor no longer had to photocopy work for ABET documentation purposes prior to returning the graded documents.

Student access to professors associated with remotely-taught courses was still one more concern. On campus, students are able to visit faculty during office hours as well as through scheduled appointments. For the students in France, two "online" office hours were scheduled each week. These office hours were purposely scheduled so that only students in France would have access to the professor at the time via phone, e-mail, and the Internet. The student in France would call the professor and "visual" communication was also established using either DyKnow or GoToMeeting and the TabletPC. This allowed the students and the professor to transmit images and equations. Initially a "white board" product was tried since it could provide two-way visual imaging. This, however, was ineffective due to large time delays and problems switching control between Grove City and France. For the first year, the students in France used the online office hours as frequently as the students on the Grove City campus. During the second year, however, the students in France did not use the online office hours very often. Instead, students occasionally e-mailed questions about homework and concepts addressed in class to the professor. Since exam scores did not appear to be affected by the reduction in office hour usage, it may simply be that this group relied upon learning from other fellow students, a skill that is beneficial when working in a team environment.

The final concern was whether a study-center approach was sufficient or if a full immersion model is preferable. The study center approach has its definite advantages. Students could more easily be held to the same regulations and GCC code of conduct as those students on campus. This, however, does require a great deal of effort and time by the resident professors. Two students were selected each year that would act as resident assistants, helping to relieve some of the burden. These students were selected through a process involving faculty input and examination of the student's campus behavior. Still, a full immersion model does permit the student to become more intimately involved in a foreign culture. Students from both years were 
asked to evaluate this through a survey. The question posed was "Do you feel that you are gaining the benefits of living in a foreign country even though essentially all courses are taught by GCC faculty and exposure to French students/faculty is limited?" From those responding the first year, all nine responses were overwhelmingly positive and thought the program definitely provided exposure to the culture and environment of a foreign country. From the second year responses, seven of the fifteen agreed that the opportunities offered by the program were very positive and provided good access to life abroad. Four of the fifteen thought the program was adequate, but would have enjoyed more exposure. Several admitted that some of the responsibility fell to the student and that the lack of exposure was a result of not taking the initiative to venture outside their "comfort zone." The remaining four responses felt the program needed more immersion in the foreign experience.

\section{Additional Benefits}

As with many programs, additional "surprising" benefits are often found. The junior study abroad program for mechanical engineering students is no exception. Several positive unexpected results occurred. One of these was associated with exposing students to technologies used in global communication beyond the cell phone. For Fluid Mechanics, students worked on projects for the course. The first year, teams were composed of members within the same country. However, each team was expected to present their findings orally through a Power Point presentation. Students had to use the tools available for the remotely-taught course in order to project the presentation simultaneously in both countries. They learned to communicate better through oral means instead of demonstrating with hand motions and facial expressions. These skills will be useful in their futures as they find the need to communicate with colleagues and potential clients located in different locations, be it in the same or a different country. For the second year, the project required team members from both countries in each group. This added a level of complexity since communication prior to the presentation had to be made typically via e-mail. In addition, the presentation involved persons from different countries requiring coordination to deliver a smooth, contiguous presentation. All teams did exceedingly well and once again acquired skills that will be useful in their future.

A second benefit was higher term GPAs for some students who studied in France. For the first year, all twelve participating students increased their term QPA up when compared to the previous Spring semester. The average increase was $0.77(\mathrm{~N}=12, \mathrm{SD}=0.30)$. With the drive for strong overall GPAs, this was definitely a benefit. Yet, one must consider what those staying on campus experienced. For those on campus, the mean increase in term GPA was $0.32(\mathrm{~N}=33$, $\mathrm{SD}=0.41)$. A t-test revealed a statistical difference between the two groups $(\mathrm{t}((43)=3.49$, $\mathrm{p}=0.00098$ ). Through careful consideration, it is believed that this improvement was associated with exposing students to other peers within the same major 24/7 and hence having easy access to study partners, a result of the study center approach. For the second year, eleven of the fifteen students also experienced an increase in their term GPA. The mean increase for this group was 0.52 . Still, four students saw a drop in term GPA with a mean value of -0.23 . When the complete group of those studying in France was compared to those studying on campus, no statistical difference was seen $(\mathrm{t}(27)=0.29, \mathrm{p}=0.78)$. Students who participated in this program commented that the model improved their study skills. 
Finally, students were able to make invaluable contacts with potential employers. Three students from the first year's program were offered the opportunity of internships with Poclain Hydraulics, Inc., a French based company. Two students took advantage of this opportunity and interned in France for the summer of 2007. In addition, several job offers for full time employment after graduation were linked to this contact. This also benefited students that were on campus since interviews were extended to some of them as well.

\section{Improvements for the Future}

As one assesses the results from the first two years of this program, areas for improvement are clarified. The increase in the number of students desiring additional immersion into the culture of the foreign country indicates the need to creatively address this issue. More deliberate interactions with professors and students at the University of Nantes could help to reduce this concern. Possibly coordinating a team project between the two facilities could be effective. A second improvement could be associated with the Engineering Management course. During the second year, another on campus professor assisted one of the resident faculty through remotelyteaching several lectures. The students enjoyed the interactions with an additional professor. The option of having the course team taught with lectures delivered remotely and the resident professor organizing facility site visits could definitely be a positive change. This would also free up some time for the already heavy-burdened resident professor. Finally, the program could be expanded to involve additional engineering and science majors. For the second year, the program was increased to incorporate business majors. Still, opening this opportunity to other technical majors will be invaluable.

\section{Summary}

International experience is becoming more of a need instead of a want. Providing this opportunity to all majors becomes a priority. At Grove City College, reduced options for certain majors motivated the Director of the Office of International Education to pursuit a new approach, meeting both the needs of academics and international exposure. A semester-long, study-center approach was developed and implemented for the past two years. From all observed results, the program is a success. Academic effectiveness and rigor are maintained while providing great opportunities to the student for exploring different cultures. Although full immersion options provide the maximum cultural experience, the study-center approach fills a niche that opened doors for mechanical engineering students to study abroad while remaining "in sync" with peers on campus.

\section{Bibliography}

1. Bremer, Darlene, “Engineering the World,” International Educator, Nov. - Dec. 2007, pp. 30 - 37.

2. Reese, Donna, Allen Greenwood, and Mary Emplaincourt, “A Portfolio of Study Abroad Options for Engineering Students to Gain International Experience," Proceedings of the 2007 American Society for Engineering Education Annual Conference, 2007. 
3. Gattis, Carol and Findlay Edwards, "Lessons Learned: Our First Engineering Study Abroad Program," Proceedings of the 2007 American Society for Engineering Education Annual Conference, 2007.

4. Ellzey, Janet L., Ted A. Aanstoos, and Kathy J. Schmidt, "Educating the Global Engineer: A New International Program at the University of Texas at Austin," Proceedings of the 2005 American Society for Engineering Education Annual Conference, 2005.

5. http://www.lafayette.edu.

6. Nasr, Karim, Joel Berry, Giancarlo Taylor, William Webster, Raghu Echempati and Ram Chandran, "Global Engineering Education Through Study-Abroad Experiences: Assessment and Lessons Learned," Proceedings of the 2002 American Society for Engineering Education Annual Conference, 2002.

7. http://www.bu.edu/abroad/programs/germany/dresden/dresden_progs/index.html.

8. http://www.eng.iastate.edu/intlprogs/.

9. http://ww.eng.bham.ac.uk/chemical/ug/chemeng_is.htm.

10. Grandin, John, "International Dual Degree Programs: The University of Rhode Island," Proceedings of the 2007 American Society for Engineering Education Annual Conference, 2007.

11. Connell, Christopher, "Georgia Tech's Well-Engineered Engagement with the World," International Educator, Nov. - Dec. 2007, pp. $38-46$. 